\title{
Genetic diversity of wild, weedy and cultivated forms of Brassica rapa
}

\author{
J. H. CROUCH, B. G. LEWIS†, D. J. LYDIATE AND R. MITHEN* \\ Brassica and Oilseeds Research Department, John Innes Centre, Colney, Norwich NR4 7UJ and † School of Biological \\ Sciences, University of East Anglia, Norwich NR4 7TJ, U.K.
}

\begin{abstract}
Restriction Fragment Length Polymorphisms (RFLPs) were used to study the genetic diversity within and between accessions of 'wild' and cultivated B. rapa. Two of the wild accessions were likely to be escapes from cultivation because of their geographical origins (Argentina and California). The nature of the other three wild accessions (from Turkey, Algeria and Sicily) was not known. Principal components analysis placed the Argentinian, Californian and Turkish accessions within a cluster which contained all the cultivated forms of $B$. rapa. The other two $B$. rapa accessions were genetically divergent and, on the basis of their RFLP genotypes, would have been considered to be more distant from the cultivated forms of $B$. rapa than accessions of $B$. nigra and $B$. montana. The implications of these results for germplasm conservation, selection of material for breeding programmes and phylogenetic studies on the origin of Brassica crops are discussed.
\end{abstract}

Keywords: Brassica rapa, diversity, RFLPs, wild germplasm.

\section{Introduction}

Recent advances have been made in Brassica taxonomy based upon RFLPs. Comparisons between wild and cultivated accessions of $B$. olerace $a$ L. and $B$. rapa $\mathrm{L}$. have led to hypotheses concerning the site of domestication of Brassica crops and their subsequent spread to other geographical regions (Song et al., 1988, 1992; Warwick \& Black, 1991). Wild forms of both $B$. oleracea and $B$. rapa are difficult to distinguish from relatively recent escapes from cultivation (Mitchell, 1976). This has led to the inaccurate description of many accessions in germplasm collections as being 'wild', whereas they are weedy remnants of previous cultivations. This may lead to incorrect deductions concerning the origin of cultivated taxa. It may also lead to an underestimation of the relative amounts of genetic diversity within and between wild and cultivated forms of crop species which has implications for genetic conservation and the choice of genotypes for breeding programmes.

To examine how incorrect identification of Brassica accessions may lead to problems with deducing evolutionary relationships we obtained from germplasm collections six accessions of $B$. rapa which were described as 'wild' and compared these with cultivated

*Correspondence. taxa (Table 1). Five of the wild accessions were interfertile with $B$. rapa and on the basis of their morphology, aliphatic glucosinolate content and cytology were consistent with being classified as $B$. rapa L. (R.F. Mithen and J. H. Crouch, unpublished data). A sixth 'wild' B. rapa accession from Egypt (UPM 4623) was found to be $B$. juncea Coss. \& Czern. Of the five wild accessions, one was collected in Argentina and one in California. These are very likely to be escapes from cultivation as it is highly improbable that wild $B$. rapa occurs in the New World. The other three accessions were collected from Turkey, Sicily and Algeria. The accession from Turkey was collected in arable fields and may also be an escape from cultivation (Öztürk $e t$ al., 1985). The accession from Sicily was collected from a road verge. No information is available concerning the origin of the Algerian accession.

\section{Materials and methods}

Plants were grown in John Innes No. 1 compost in insect-proof glasshouses in a $18^{\circ} \mathrm{C}$ day $/ 12^{\circ} \mathrm{C}$ night temperature regime. Supplementary lighting was provided during the winter. Total genomic DNA preparations were made from freeze-dried leaf material of between two and five individuals from each accession. EcoRI-restricted DNA fragments were separated by electrophoresis and were capillary blotted 
Table 1. Origin of Brassica accessions used in the present study

\begin{tabular}{lllll}
\hline Accession & Code no. & Genome & Origin & Description and donor number \\
\hline $\begin{array}{l}\text { B. rapa subspecies } \\
\text { rapifera }\end{array}$ & 99 & & & \\
$\begin{array}{l}\text { oleifera } \\
\text { oleifera }\end{array}$ & 29 & $A$ & Netherlands & Stubble turnip \\
oleifera & 529 & $A$ & Germany & Oilseed rape cv. Makelsberg \\
italica & 532 & $A$ & Canada & Oilseed rape cv. Tobin \\
chinensis & 189 & $A$ & Canada & Oilseed rape cv. Parkland \\
chinensis & 333 & $A$ & & Vegetable cv. Brocoletto, HRI 6218 \\
sylvestris & 699 & $A$ & Asia & Chinese cabbage var. chinesis, IPSR \# R-C-26 \\
sylvestris & 73 & $A$ & Asia & Chinese cabbage cv. Grannaat \\
sylvestris & 74 & $A$ & Turkey & Wild, UPM 6278 \\
sylvestris & 75 & $A$ & Argentina & Wild, UPM 5903 \\
sylvestris & 76 & $A$ & Sicily & Wild, UPM 6652 \\
& 79 & $A$ & California & Wild, UPM 6464 \\
Outgroups & & & & Wild, UPM 1742 \\
B. nigra & 179 & $B$ & Greece & Ecotype, BGRC 34180 \\
B. nigra & 211 & $B$ & Germany & Wild, BGRC 32960 \\
B. montana & 196 & $C$ & France & Wild, BOS 12 \\
\hline
\end{tabular}

Germplasm collections prefixes: HRI: Horticulture Research International, UK; IPSR: Institute of PJant Science Reserch, UK; UPM: Universidad Politecnica Madrid, Spain; BGRC: Institut für Pflansenbau, Germany; BOS: Institut National de la Recherche Agronomique, France.

Table 2. List of probes used in the present study, the number of RFLPs they detected and the RFLP alleles unique to either B. rapa subsp. sylvestris no. 75 or no. 76

\begin{tabular}{lccc}
\hline Probe & $\begin{array}{c}\text { Polymorphic } \\
\text { alleles }\end{array}$ & \multicolumn{2}{c}{ Alleles specific to } \\
No. 75 & No. 76 \\
\hline pW2E12 & 8 & - & 1 \\
pW9A2 & 8 & 1 & - \\
pW7B6 & 16 & 1 & 1 \\
pW1F6 & 14 & - & - \\
pW2B7 & 16 & 1 & 1 \\
pW2A11 & 16 & - & - \\
pO10 & 8 & - & 2 \\
pO112 & 10 & 1 & - \\
pO118 & 7 & - & 1 \\
pR54 & 13 & - & - \\
pR115 & 7 & - & 1 \\
\hline
\end{tabular}

onto a nylon filter. Filters were probed with 11 anonymous gDNA probes derived from libraries of small (0.8-1.6 kb) PstI-restricted fragments from B. napus L., $B$. oleracea and $B$. rapa. The probes used for detecting RFLPs are listed in Table 2. Full details of DNA extraction, blotting and Southern hybridization are provided by Magrath et al. (1994).
Each restriction fragment was considered as a unit character and was used to create a binary matrix. This matrix was used for principal components analyses with the aid of a program provided by $\mathrm{M}$. Ambrose (John Innes Centre, Norwich) written within the GENSTAT 5 software (Rothamsted Experimental Station, England). Similarity coefficients were calculated according to the Jaccard coefficient (as described in Gower \& Legendre, 1986) for all possible pairwise comparisons between genotypes (Table 3). The first and second principal components were then graphically presented (Figs 2 and 3). Similar methods of data analysis have been adopted by Wetton et al. (1987), Song et al. (1990) and Lashermes et al. (1993).

\section{Results}

One hundred and twenty-three restriction fragments were scored across all accessions. The Brassica accessions tested showed a very high level of polymorphism (Fig. 1) and no fragments were common for all accessions. The wild accessions from Sicily and Algeria contained several unique restriction fragments (Table 2). With the exception of one unique fragment which occurred in B. rapa subsp. italica no. 189 , none of the cultivated subspecies or the accessions from California, Argentina and Turkey possessed any unique restriction fragments.

(C) The Genetical Society of Great Britain, Heredity, 74, 491-496. 
Table 3. Simiarity matrix of $D$ values for $B$. nigra $(2,3)$, B. montana $(1,4,31)$, B. rapa subspp. rapifera $(5,10)$, European oleifera $(6,7)$, Canadian oleifera $(8,9)$, italica $(17,18)$, chinensis $(16,19,20)$ and $B$. rapa subsp. sylvestris accessions collected from California $(11,12)$, Argentina $(13,14,15)$, Turkey $(21,30)$, Algeria $(22,23,24)$, Sicily $(25,26,27,28,29)$

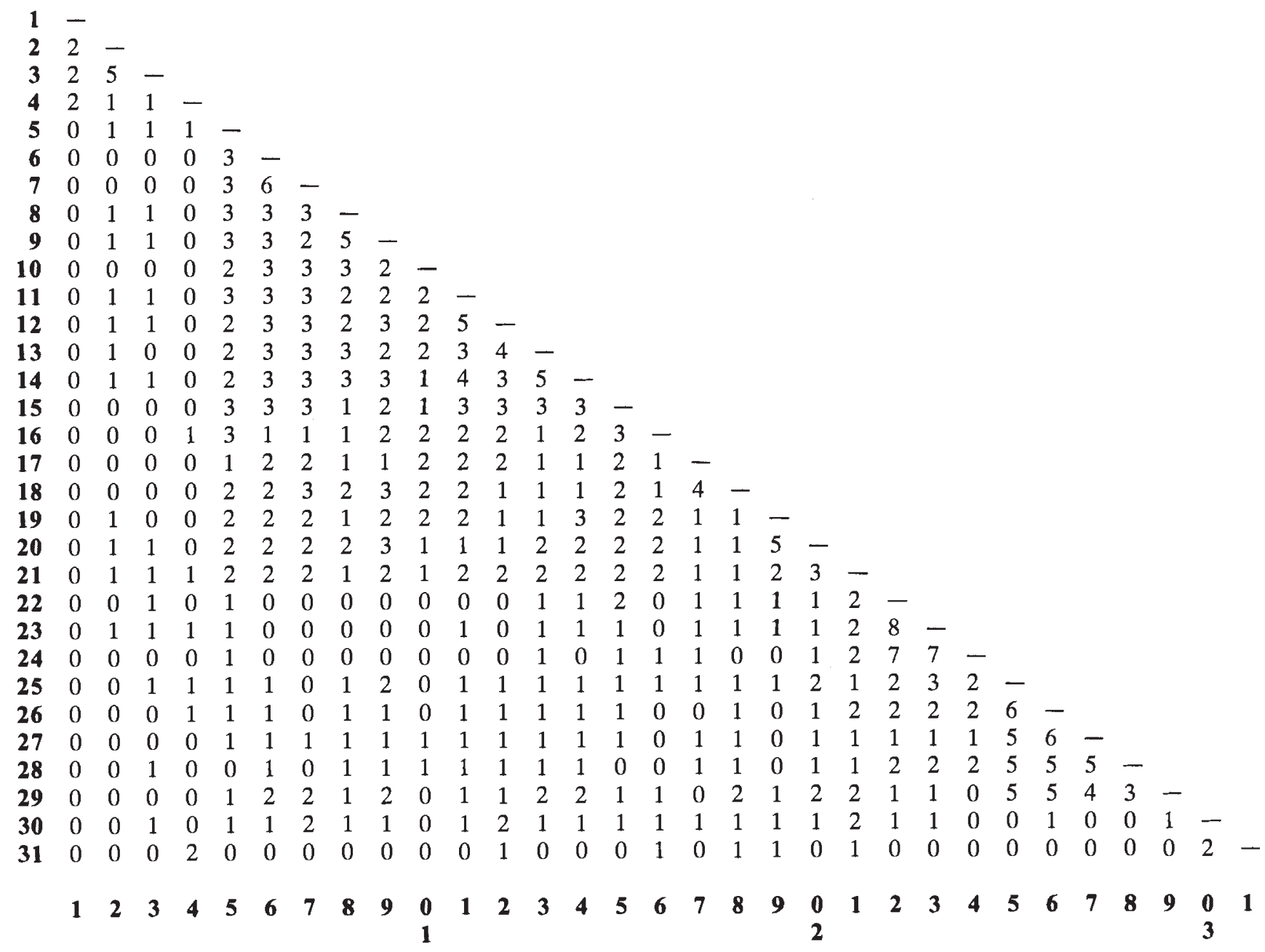

Principal components analysis clustered the accessions into several groups (Fig. 2). All seven cultivars of $B$. rapa clustered together, along with the accessions of $B$. rapa collected in Argentina and California, suggesting, as expected, that these two accessions represented weedy escapes as opposed to true wild forms of $B$. rapa. The Turkish accession of $B$. rapa was also situated close to all the cultivars. The other wild accessions from Sicily (no. 75) and Algeria (no. 76) formed two separate clusters which were more distant from the cultivated and weedy $B$. rapa accessions than the outgroup represented by $B$. montana Pourr. and $B$. nigra (L.) Koch. The first principal component explained 25.5 per cent of the variation in RFLPs and separated the wild accessions from Sicily and Algeria from the other accessions. The second principal component explained 18.3 per cent of the variation and separated the accessions from Algeria and Sicily from each other. Further statistical analysis did not significantly alter the results.

Closer examination of the principal components analysis (Fig. 3) revealed grouping of taxa within the main cluster containing the cultivated and weedy $B$. rapa accessions. The $B$. rapa subsp. oleifera (Metzg.) Sinsk accessions were relatively distant from the $B$. rapa subsp. chinesis (L.) Makino accessions, with the other weedy and cultivated taxa falling between these two groups. These results are similar to those of Song et al. (1990) in which Asiatic forms of B. rapa were shown to be phylogentically distinct from $B$. rapa subsp. rapifera (Metzg.) Sinsk and subsp. oleifera. The B. rapa subsp. oleifera cultivars from Canada were divergent from the European cultivar (Fig. 3). Considerable variation was observed within the $B$. rapa 


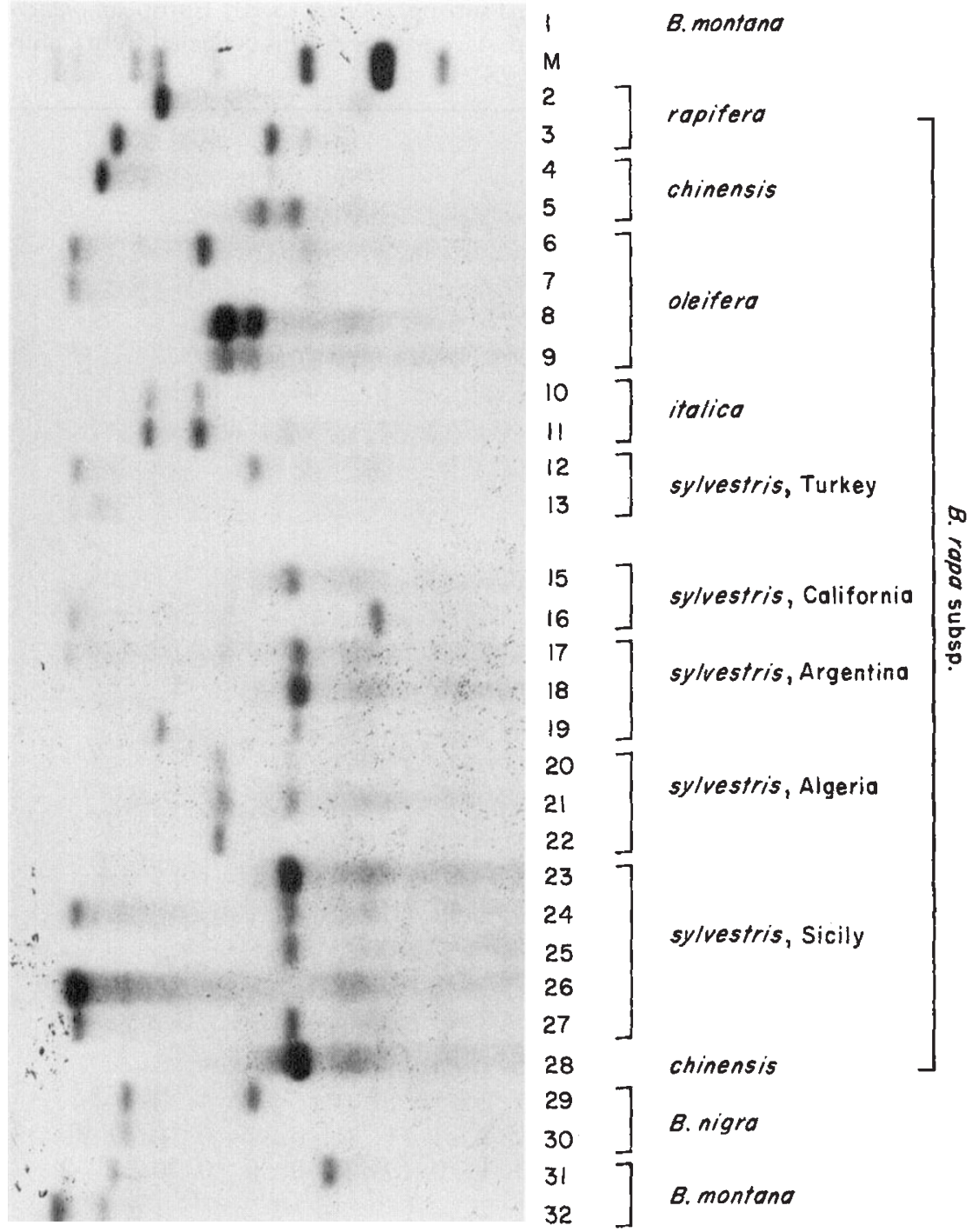

Fig. 1. Southern blot hybridization of EcoRI-restricted genomic DNA from $B$.rapa, B. nigra and B. montana outgroups probed with clone $\mathrm{pW} 199$. subsp. italica cv. brocolleto (no. 189). Further analyses of diversity within cultivated forms of $B$. rapa require more extensive studies with a greater number of accessions.

\section{Discussion}

The principal components analysis in this study was based on the presence or absence of 123 restriction fragments. Song et al. (1990) concluded that the analysis of a limited number of restriction fragments (less than that used in this study) was sufficient to describe the major sources of genetic diversity between Brassica accessions. It is likely, therefore, that an increase in the number of restriction fragments scored (through either an increase in the number of probes or by the use of additional restriction enzymes) would not significantly alter the conclusions. Furthermore, the probes used in this study were chosen to hybridize to fragments throughout the $B$. rapa genome (D. Lydiate, unpublished data) in order that the results would not be biased by the detection of RFLPs within selected parts of the genome, which would be particularly problematical if such regions were highly conserved. However, the very high levels of polymorphism (see Table 2) suggest that hybridization to conserved regions of the genome was not a problem. Thus, we feel that the major conclusions of this study regarding the genetic similarities and differences between the wild and cultivated accessions are valid and would not be significantly altered by increasing the number of restriction fragments detected. 


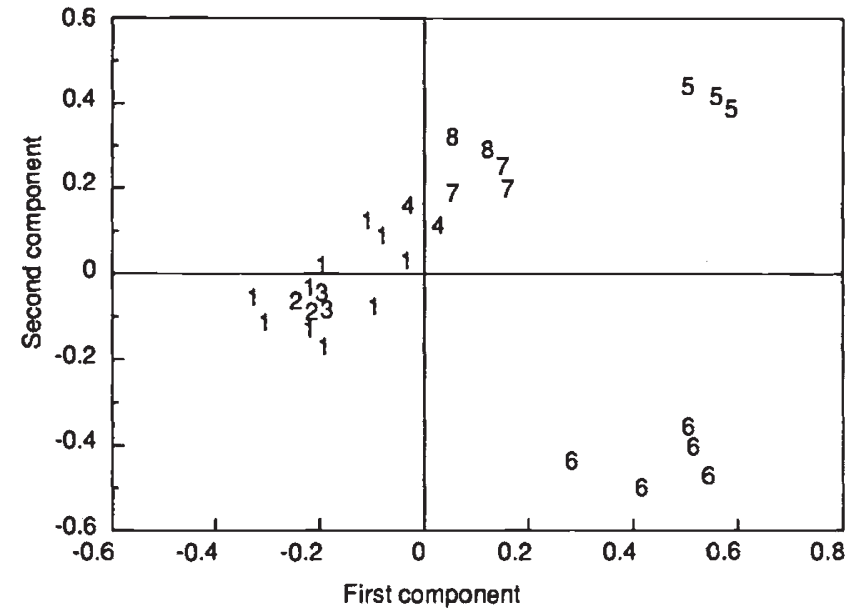

Fig. 2. Plot of first and second principal components showing relationships between all accessions tested: 1 , cultivated subspecies of $B$. rapa; 2, B. rapa subsp. sylvestris 79 (California); 3, B. rapa 74 (Argentina); 4, B. rapa 73

(Turkey); 5, B. rapa 76 (Algeria); 6, B. rapa 75 (Sicily); 7, B. montana; 8, B. nigra.

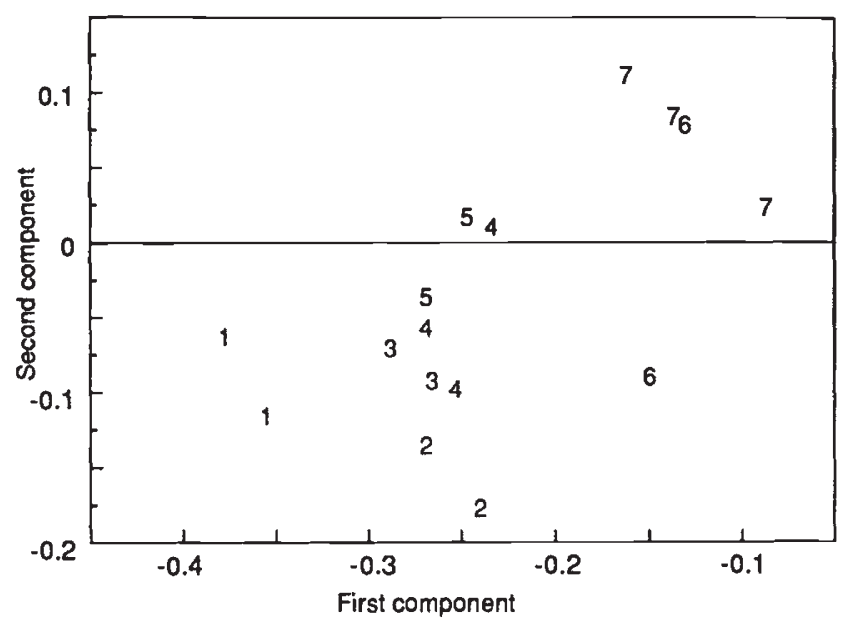

Fig. 3. Plot of first and second principal components showing relationships between cultivated and weedy accessions tested: $B$. rapa subspecies 1, oleifera (Europe); 2 , oleifera (Canada); 3, sylvestris (California); 4, sylvestris (Argentina); 5, rapifera; 6, italica; 7, chinensis.

The RFLPs and principal components analyses have suggested that two accessions of $B$. rapa are genetically distant from other forms of B. rapa. This result is supported by a study of secondary metabolites (Rouxel et al., 1991) in which both of these accessions possessed indole compounds which are not normally found within B. rapa. Furthermore, both accessions possess high levels of resistance to the fungal pathogen Leptosphaeria maculans (Desm.) Ces. et de Not. which has not previously been described in $B$. rapa (Rouxel et al., 1991; Crouch et al., 1994). Both accessions have been used in breeding programmes of $B$. rapa and in the development of synthetic forms of $B$. napus by interspecific hybridization with $B$. oleracea (Crouch et al., 1994). These two accessions, therefore, seem to represent forms of $B$. rapa which are genetically distinct from cultivar and weedy types, and this raises questions concerning the phylogenetic deductions made in other studies which have used 'wild" forms of B. rapa. Sicily has been shown to be an important centre of diversity for wild C genome Brassica taxa (Mazzola \& Raimondo, 1988; Snogerup et al., 1990); this study has indicated that it may also be an important area for wild forms of $B$. rapa and suggests that further exploration is warranted.

The other three 'wild' B. rapa accessions clustered with the cultivated taxa. The accessions from California and Argentina are likely to be relatively recent escapes from cultivation as true wild forms of $B$. rapa are restricted to the Old World. It is probable that the Turkish accession is also a weedy escape from cultivation as opposed to a true wild form of $B$. rapa. However, results such as this have led to the suggestion that wild accessions such as the Turkish accession may represent the progenitors of cultivated forms of $B$. rapa (e.g. Song et al., 1990). In these studies, it is likely that a comparison is only being made between cultivars and a weedy escape from cultivation. In addition to confusion between wild and weedy accessions, it is noteworthy that one of the 'wild $B$. rapa' accessions which was examined was in fact $B$. juncea.

In studies of crosses between wild and cultivated tomatoes, deVicente \& Tanksley (1993) described transgressive segregation in an $F_{2}$ population for a number of agronomic traits. It was shown that the wild species carried alleles for several agronomically important yield characters although this was not apparent from their phenotypes. It is likely that a similar phenomenon occurs in other crop species. RFLP analyses as described in this study may provide a means to select genetically divergent wild forms of crops, such as the B. rapa accessions from Sicily and Algeria, in which useful alleles are present but which are not phenotypically expressed. This analysis may also provide a means to make informed choices concerning priorities for germplasm conservation and characterization.

The confusion in identification of wild $B$. rapa accessions is common to several other crop species. For example, wild forms of Vigna unguiculata (L.) Walp. were once only considered to occur in West Africa whereas it is now known that the greatest degree of genetic diversity in this species is actually found in wild forms which are abundant in southern Africa (Mithen \& Kibblewhite, 1993; Vaillancourt et al., 
1993). Many of the previously described 'wild' accessions of $V$. unguiculata are naturalized cowpeas. The recent interest in the conservation of wild crop relatives has resulted in an increase in the number of accessions in gene banks which are described as being 'wild'. Many of these are likely to be recent escapes from cultivation and may represent no greater levels of genetic diversity than that of cultivated forms and will lead to an underestimation of the genetic divergence between crops and their wild relatives (e.g. Letschert \& Fese, 1993). Studies on genetic diversity using RFLPs and other molecular markers may indicate wild accessions which are the most genetically divergent from cultivars and which contain unique alleles. These accessions may be the most productive material for seeking useful agronomic characters such as pest and disease resistance, particularly if the introgression of these characters into cultivars can be aided through the use of molecular markers.

\section{Acknowledgements}

The authors are grateful to Professor C. GomezCampo (Universidad Politecnica Madrid) for providing seeds and for helpful discussion concerning the distribution of wild $B$. rapa populations, to $\mathrm{Dr}$ Rouxel (INRA, Rennes) for providing seeds and to Dr M. Ambrose for assistance with data analysis. RFLP probes were provided by Zeneca Ltd. Technical assistance from R. Magrath, I. Parkin and A. Sharpe is gratefully acknowledged. J.C. received financial support from Zeneca Ltd and the Ministry of Agriculture, Fisheries and Food.

\section{References}

CROUCH, J. H., LEWIS, B. G. AND MITHEN, R. F. 1994. The effect of A genome substitution on the resistance of Brassica napus to infection by Leptosphaeria maculans. Pl. Breed., 112, 265-278.

DEVICENTE, M. C. AND TANKSLEY, S. D. 1993. QTL analysis of transgressive segregation in an interspecific tomato cross. Genetics, 134, 585-596.

GOWER, J. C. AND LEGENDRE, P. 1986. Metric and Euclidean properties of dissimilarity coefficients. J. Classification, $\mathbf{3}$, 5-48.

LASHERMES, P., CROS, J., MARMEY, P. AND CHARRIER, A. 1993. Use of random amplifed DNA markers to analyse genetic variability and relationships of Coffea species. Genet. Res. Crop Evol., 40, 91-99.

LETSCHERT, J. P. W. AND FESE, L. 1993. Analysis of morphological variation in wild beet (Beta vulgaris L.) from Sicily. Genet. Res. Crop Evol., 40, 15-24.

MAGRATH, R., BANO, F., MORGNER, M., PARKIN, 1., SHARPE, A., LISTER, C., DEAN, C., TURNER, J., LYDIATE, D. AND MITHEN, R. 1994. Genetics of aliphatic glucosinolates. I. Side chain elongation in Brassica napus and Arabidopsis thaliana. Heredity, 72, 290-299.

MAZZOLA, P. AND RAIMONDO, F. M. 1988. A new species of Brassica from Sicily. Lagascalia, 15, 249-251.

MiTCHELl, N. D. 1976. The status of Brassica oleracea L. subsp. oleracea (wild cabbage) in the British Isles. Watsonia, 11, 97-103.

MiTHEN, R. F. AND kibBlewhite, H. R. 1993. Taxonomy and ecology of Vigna unguiculata in south-central Africa. Kirkia, 14, 100-113.

OZTÚRK, M., HINATA, K., TSUNODA, S. AND GOMEZ-CAMPO, c. 1985. A general account of the distribution of the Cruciferous plants in Turkey. E. U. Faculty Sci. J. Ser. B, 6, 87-98.

ROUXEL, T., KOLLMANN, A., BOULIDARD, L. AND MITHEN, R. F. 1991. Abiotic elicitation of indole phytoalexins and resistance to Leptosphaeria maculans within Brassiceae. Planta, 184, 271-278.

SONG, K. M., OSBORN, T. C. AND WiLliAmS, P. H. 1988. Brassica taxonomy based on nuclear restriction fragment length polymorphisms (RFLPs). 2. Preliminary analysis of subspecies within $B$, rapa (syn. campestris) and $B$. oleracea. Theor. Appl. Genet., 76, 593-600.

SONG, K., OSBORN, T. C. AND WILliAMS, P. H. 1990. Brassica taxonomy based on nuclear restriction fragment length polymorphisms (RFLPs). 3. Genome relationships in Brassica and related genera and the origin of $B$. oleracea and $B$. rapa (syn. campestris). Theor. Appl. Genet., 79, 497-506.

SONG, K. AND OSBORN, T. C. 1992. Polyphyletic origins of Brassica napus: new evidence based on organelle and nuclear RFLP analyses. Genome, 35, 992-1001.

SNOGERUP, S., GUSTAFSSON, M. AND VON BOTHMER, R. 1990. Brassica sect. Brassica (Brassicaceae). 1. Taxonomy and variation. Willdenowia, 19, 271-365.

VAILlANCOURT, R. E., WEEDAN, N. F. AND BARNARD, J. 1993. Isozyme diversity in the cowpea species complex. Crop Sci., 33, 606-613.

WARWICK, S. I. AND BLACK, L. D. 1991. Molecular systematics of Brassica and allied genera (subtribe Brassicinae, Brassiceae)-chloroplast genome and cytodeme congruence. Theor. Appl. Genet., 82, 81-92.

WETTON, J. H., CARTER, R. E., PARKIN, D. T. AND WALTERS, D. 1987. Demographic study of a wild house sparrow population by DNA fingerprinting. Nature, 327, 147-149. 